\title{
Cranial electrical stimulation for the treatment of insomnia, anxiety, and depression symptoms in adults
}

\author{
Jesús A. Moo-Estrella*, and María F. Pérez-Pichardo \\ Sleep Laboratory, School of Psychology, Universidad Autónoma de Yucatán, Mérida, Yucatán, Mexico
}

\begin{abstract}
Background: Clinical advantages of the cranial electrical stimulation (CES) are not yet clear. Objective: The objective of the study was to know the effects as a result of the CES intervention for the treatment of insomnia symptoms, anxiety, and depression. Method: Twenty-four individuals agreed to participate in the study, all of them with initial insomnia diagnosis (ISDC-2), with an average age of 32.10 ( \pm 14.24$)$ years old (58\% women), distributed in control $(n=11)$ and experimental group ( $n=13$ ). The intruments used were Beck's depression inventory, State-Trait Anxiety Inventory, the Insomnia Severity Index, and the Insomnia Symptoms Questionnaire. A CES device (Fisher Wallace-100) was given to each participant for its use at nights and mornings (20 min each session) for 10 days. Results: Insomnia symptoms decreased significantly in both the control and experimental groups $(p<0.01)$, but only in the experimental group there was a significant reduction in the severity of insomnia $(p<0.05)$. According to the effect size (Cohen's $d$ ), the experimental group had a larger effect in the insomnia severity and a moderated effect for anxiety and depression. The placebo group had a small effect in anxiety and a medium in insomnia and depression. Conclusions: The CES effect is superior to placebo to reduce the insomnia severity, but it is no different from placebo for anxiety and depression symptoms.
\end{abstract}

Key words: Anxiety. Cranial electrical stimulation. Depression. Insomnia.

\section{Estimulación eléctrica craneal para el tratamiento de los síntomas de insomnio, ansiedad y depresión en adultos}

\section{Resumen}

Introducción: La estimulación eléctrica craneal (EEC) es una técnica neurofisiológica que consiste en enviar pulsos de corriente eléctrica (<4 mA) al cerebro a través de electrodos colocados en el cuero cabelludo. Sin embargo, los alcances clínicos de la EEC como tratamiento para las alteraciones afectivas y del sueño aún no están claros. Objetivo: Conocer los efectos del uso de la intervención EEC para el tratamiento sobre los síntomas de insomnio, ansiedad y depresión. Método: Participaron 24 sujetos que cumplieron los criterios de insomnio de acuerdo con el ISDC-2, con una edad promedio de 32.10 ( \pm 14.24 ) años (58\% mujeres), divididos en grupo control $(n=11)$ y grupo experimental $(n=13)$. Los instrumentos utilizados fueron el inventario de depresión de Beck, el cuestionario de ansiedad-estado (Spielberger), el Índice de Severidad de Insomnio y un cuestionario de síntomas de insomnio. Cada participante recibió un dispositivo de EEC (FW-100) para

Correspondence:

*Jesús A. Moo-Estrella

E-mail: jmestre@correo.uady.mx
Date of reception: 09-05-2019

Date of acceptance: 18-01-2020

DOI: $10.24875 / R M N .20000083$
Available online: 18-05-2020 Rev Mex Neuroci. 2020;21(3):104-110 www.revmexneurociencia.com 1665-5044/ @ 2020. Academia Mexicana de Neurología A.C. Published by Permanyer. This is an open access article under the CC BY-NC-ND license (http://creativecommons.org/licenses/by-nc-nd/4.0/). 
su uso en la noche y en la mañana (20 minutos cada sesión), durante 10 días, empleado durante 20 minutos cada noche antes de dormir y 20 minutos al despertar. Los cuestionarios fueron aplicados antes y después del tratamiento. Resultados: Los síntomas de insomnio disminuyeron significativamente tanto en el grupo control como el experimental $(p<0.01)$, pero solo en el grupo experimental hubo una reducción significativa de la gravedad del insomnio $(p<0.05)$. Con base en el tamaño del efecto (d de Cohen), el grupo experimental tuvo un efecto mayor en la reducción de la gravedad del insomnio y un efecto moderado para la ansiedad y la depresión. En el grupo de placebo (control) la magnitud del efecto fue leve para la ansiedad y moderada tanto para el insomnio como para la depresión. Conclusiones: El efecto EEC fue superior al placebo para reducir la gravedad en el tratamiento del insomnio, pero no fue diferente al placebo y tuvo efectos similares en la disminución de los síntomas de ansiedad y depresión.

Palabras clave: Ansiedad. Estimulación eléctrica craneal. Depresión. Insomnio.

\section{Introduction}

Anxiety, depression, and insomnia are considered to be among the alterations that generate disturbance in people who suffer them ${ }^{1,2}$. It is estimated that these changes may be present even in one-third of the world's population ${ }^{3-5}$, and in Mexico, they can reach similar numbers ${ }^{6-8}$. These disorders are associated with the pathophysiology of the brain. Insomnia and anxiety include an increase of emotional, cognitive, somatic, and cortical excitability 9,10 while depression is associated with the decrease of cortical activity in prefrontal areas and the anterior cingulate gyrus $^{11}$. Many interventions focus on drug treatments ${ }^{12-14}$, but they often have certain limitations, such as cost, side effects, and a decrease of its efficiency and the quality of patient's lifestyles ${ }^{15-17}$. The non-pharmacological approaches for the treatment of these disorders are diverse and its effectiveness is still in research ${ }^{18,19}$. Non-invasive brain stimulation techniques are used as an alternative to pharmacological treatment and they have shown a notable upturn in recent decades ${ }^{20}$.

Cranial electrical stimulation (CES) is a non-invasive neurophysiological technique that works through low-intensity pulses of electric current of $\leq 4$ milliamperes (mA) in frequencies from 0.5 to $15,000 \mathrm{~Hz}$, through two electrodes placed on the scalp ${ }^{21}$. The CES is safe ${ }^{22}$ and it has been employed on different disorders such as major depression, anxiety, post-traumatic stress disorder, and insomnia ${ }^{23}$. Brain stimulation with alternating current (AC) such as CES has important approaches in the treatment of anxiety, depression, and insomnia ${ }^{24}$, however, it requires greater attention on its mechanism of action, especially in clinical research.

The mechanism of the CES on clinical symptoms has been explained at different levels on the nervous system. On the one hand, it is believed that the CES affects subcortical structures such as the reticular activating system, the thalamus, hypothalamus, and limbic system $^{16,21}$. Brain imaging studies suggest a cortical deactivation in the prefrontal and parietal midline of the brain after 20 min of CES ${ }^{25}$. In addition, it is proposed that the effects of CES include both cortical and subcortical areas producing changes similar to the use of anti-anxiety medications ${ }^{26}$. At the electrophysiological level, it is observed an increase in alpha activity and a decrease in delta and beta activity ${ }^{27}$. At a biochemical level, it is suggested an increase in endorphins, adrenocorticotropic hormone, serotonin, melatonin, norepinephrine, cholinesterase, and reduction of cortisol ${ }^{21}$.

Given that the electrodes are placed over the scalp, this technique is considered a form of peripheral nerve stimulation. Although the positive effects of the CES have been observed in different levels of the nervous system, its efficacy on clinical symptoms is not yet conclusive. However, the use of the CES in the clinical practice has increased steadily in recent decades, so it is required the application of empirical studies which can be distinguished from the placebo effect.

\section{Method}

\section{Participants}

Twenty-six cases that covered the insomnia symptoms based on the International Classification of Sleep Disorders (ICSD) were considered initially ${ }^{2}$. The inclusion criteria were to be over 18 years old and the exclusion criteria were having antecedents of epilepsy, receive treatment for insomnia or drug use with effects on the central nervous system or metallic implants and/or pacemakers. Of the 26 cases, two were eliminated from the control group, for failing to comply with the age of majority and the second report of phosphenes as a side effect in the first session of the treatment of CES (Fig. 1 shows the eligibility diagram). The final sample included 24 subjects with an average age of $32.10( \pm 14.24)$ years old (58\% women), with a diagnosis of insomnia. Participants were randomized between the control 


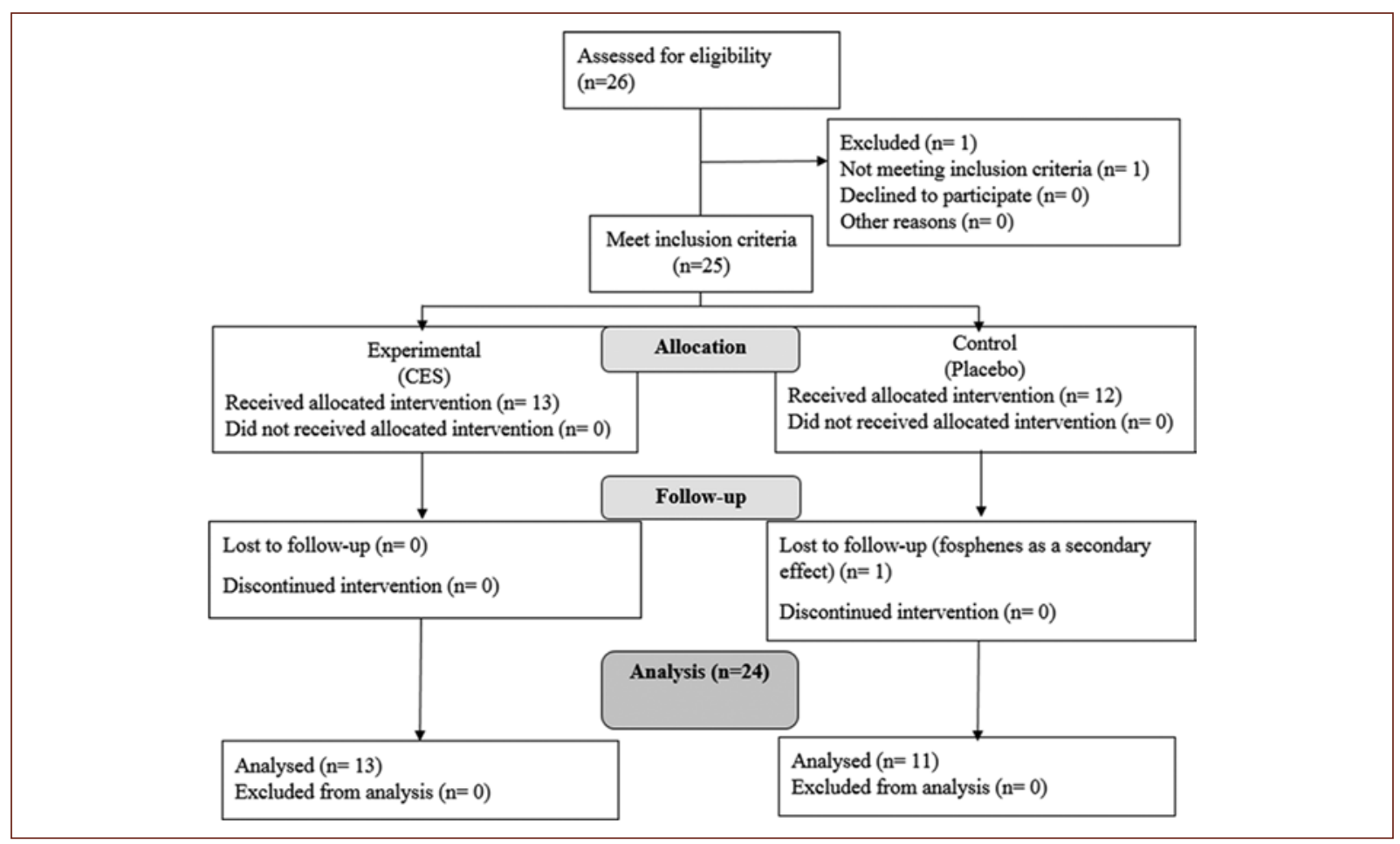

Figure 1. Flow diagram.

( $n=11)$ and experimental groups $(n=13)$ in the order, in which they arrived at the sleep laboratory. No differences in sex and age were observed between the groups.

\section{Instruments}

The study consisted of four self-administered questionnaires completed by participants to provide information on insomnia, anxiety, and depression symptoms. The first instrument is the insomnia symptoms questionnaire, based on the ICSD- $3^{2}$, which consists of 43 dichotomous questions, grouped into five factors: (1) general symptoms of insomnia, (2) psychophysiological insomnia, (3) stress-related insomnia, (4) inadequate sleep hygiene, and (5) idiopathic insomnia. These same instruments included questions related to habits and sleep schedules. The second questionnaire was the insomnia severity index ${ }^{28}$, composed of seven questions with a format of five options of response (from 0 to 4), where a high score means more severity of insomnia, considering the following cutoff points: no clinically significant insomnia (0 to 7), subthreshold insomnia (8 to 14), moderate (15 to 21), and severe (22 to 28 ).

The State-Trait Anxiety Inventory ${ }^{29}$ was administered for the evaluation of anxiety. This questionnaire includes 20 questions with four answer options ( $1=$ not at all;
2 = somewhat; 3 = moderately so; and 4 = very much so), whereas the cutoff points are high (ntsons with four -44$)$, and low $(<30)$. The inventory of depression of Beck (Beck's depression inventory) ${ }^{30}$ was used for the measurement of depression symptoms. The cutoff points are minimum (0-13), mild (14-19), moderate (20-28), and severe (29-63).

The technique was used for treatment, neuropsychological CES using the "Fisher Wallace (FW) stimulator" device FW 100 model. This device includes two electrodes which are located bilaterally in the temples of the scalp, which send small pulses of $A C$ with a square wave in three frequencies: $15 \mathrm{~Hz}, 500 \mathrm{~Hz}$, and $15,000 \mathrm{~Hz}$, with variation of the temples of the scalp, which s study was $2 \mathrm{~mA}^{21}$.

\section{Procedure}

The questionnaires were applied before and after the treatment, following the ethical guidelines according to the Official Mexican Norm NOM004-SSA3-201 in research for health. A consent letter was given for voluntary participation with freedom to withdraw at any time during the study, including information about the purpose of the study, the justification, risks and benefits and confidentiality on the individual's data in written form. The 
device was delivered to each subject for home use for 10 days. Previously held a training session in the sleep laboratory (Faculty of Psychology, Universidad Autónoma de Yucatán) indicating the use of the device for 20 min every night before bedtime and $20 \mathrm{~min}$ in the morning. For the control group, it was indicated that the therapeutic level was zero (placebo). It is worth mentioning that a brochure on sleep hygiene was provided for the two groups. During the study, participants did not receive additional treatment. At the end of the protocol, control was provided to participants in the group the device 10 days more in active mode (level 2).

The statistical test was used for data analysis Student's t-test for related samples whereas alpha minimum of 0.05 . Similarly, the effect size was analyzed to assess the relevance of the effects of intervention among groups within the practical context of research. For the effect size, following cutoff points were considered: no effect al0.20, small $=0.21-0.49$, medium effect $=0.50-0.79$, and large effect $=0.80^{31}$.

\section{Results}

A difference was found in relation to the sleep habits $(p<0.01)$ in the experimental group, which reported one more hour of sleep after the intervention (Table 1). There was a significant reduction of four symptoms of insomnia in both groups. In addition, the psychophysiological insomnia symptoms decreased in the control group ( $p=0.026)$ and severity of insomnia in the experimental group $(p=0.002)$.

In the report of anxiety symptoms, there were no differences between groups, but in depression symptoms, there was a reduction of four points in the control group $(p=0.018)$ and five points in the experimental $(p=0.016)$, as shown in table 2 .

Based on the analysis of the effect size (Cohen's d), both CES and placebo had a positive effect in reducing the symptoms, but at different levels. For the insomnia index the effect was strong in the CES group $(d=0.88)$ and moderated in the placebo group $(\mathrm{d}=0.52)$. For symptoms of anxiety, the effect was modest with the CES $(d=0.54)$ and moderated with placebo $(d=0.35)$. In both groups the effect size of depression was moderated $(d=0.69$, and $d=0.58$, respectively).

\section{Discussion}

It is suggested that the CES can have positive effects over the symptoms of anxiety, insomnia, and depression due to its influence on the limbic system and the autonomic nervous system, interconnected with the hypothalamic-pituitary-adrenal-immune axis ${ }^{32}$. However, our results, after low-voltage CES, suggest a variety on the effects on the symptoms of anxiety, depression, and insomnia. In this sense, the increase of an hour of sleep and decrease the severity of insomnia as a result of the CES are observed, but psychophysiological insomnia symptoms reduced as the result of a placebo effect. Symptoms of anxiety and depression decreased in CES group, but they were not superior to placebo group.

The increase in the time dedicated to sleep during the week supports the hypothesis that the CES changed the perception of sleep. However, there are no changes in bedtime schedules and get up to match this increase. Reporting sleeping an extra hour as the effect of the CES was consistent with the results previously obtained ${ }^{16}$. It is noteworthy that even with an increase of an hour of sleep (from 5 to $6 \mathrm{~h}$ ), they are below recommended hours of sleep time ${ }^{33}$. Possibly, these results can increase by extending the number of sessions of CES. In addition, it is proposed to consider that the application of the CES should be accompanied by strategies such as hygiene of sleep and therapy cognitive behavior to improve the effectiveness of the CES and maintain longer the positive effects on sleep ${ }^{34}$.

In relation with insomnia, our results are similar to the results of a meta-analysis study that suggests that the CES is effective for the treatment of insomnia severity ${ }^{35}$. However, we recommend to obtain objective sleep measurements to establish the physiological mechanism associated with clinical changes. Our results indicate that some types of insomnia such as the psychophysiological may improve as a result of the placebo effect. Psychophysiological insomnia is characterized by concerns over not being able to sleep, occurring particularly at the time of going to bed ${ }^{2}$. Furthermore, it is possible that placebo shifted the focus of attention: the concern to the concentration in the sense of the device, providing relaxation to fall asleep.

In relation to anxiety, some authors have suggested that the CES technique should not be used in the treatment of their symptoms unless that is used for its value as placebo ${ }^{36}$. In our study, the effect of CES improved the symptoms of anxiety, as it has been reported in the previous studies, but the effect was similar to the placebo's when analyzed the results considering the statistical significance, no statistical differences were observed. Similar results in different studies are discussed based on statistical significance, however, analysis with an alternative statistic as the $d$ Cohen $^{31}$ may 


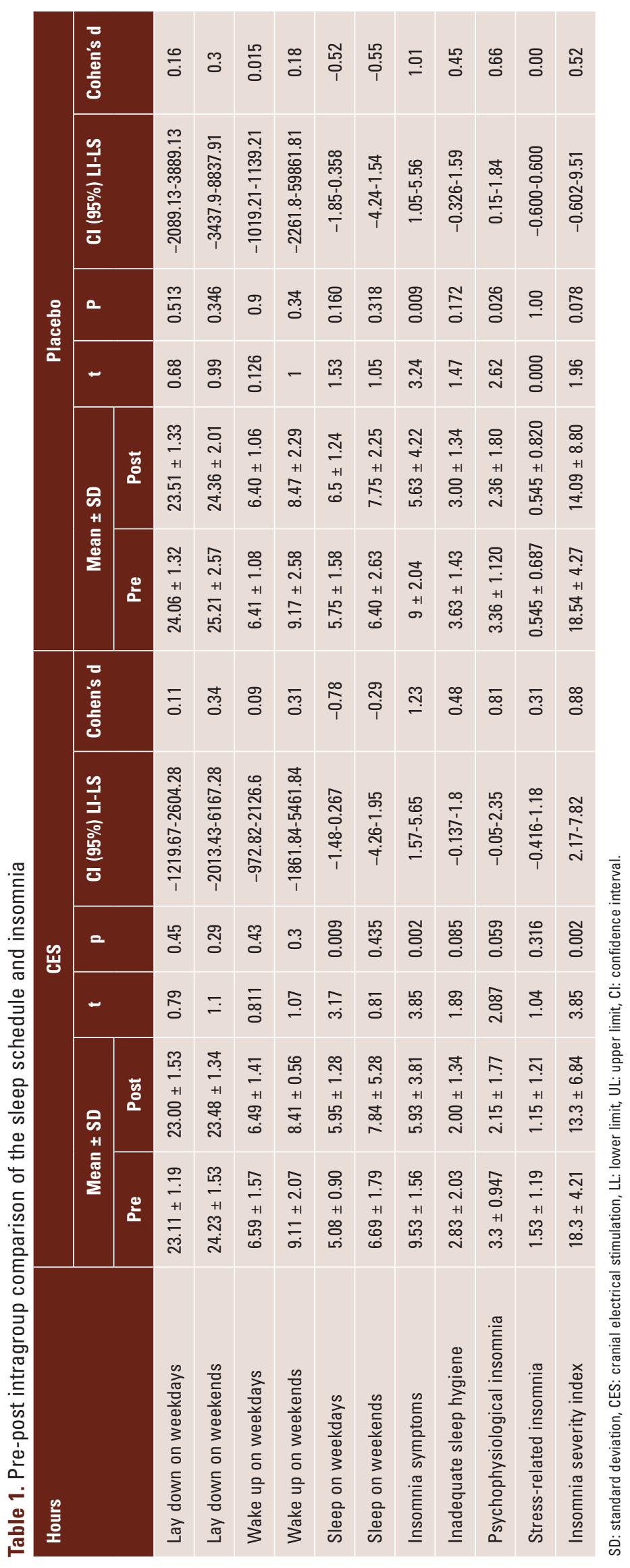


Table 2. Pre-post intragroup comparison of anxiety and depression symptoms

\begin{tabular}{|c|c|c|c|c|c|c|c|c|c|c|c|c|}
\hline \multirow[t]{3}{*}{ Hours } & \multicolumn{6}{|c|}{ CES } & \multicolumn{6}{|c|}{ Placebo } \\
\hline & \multicolumn{2}{|c|}{ Mean \pm SD } & \multirow[t]{2}{*}{$t$} & \multirow[t]{2}{*}{$\mathbf{p}$} & \multirow{2}{*}{$\begin{array}{c}\text { CI }(95 \%) \\
\text { LI-LS }\end{array}$} & \multirow{2}{*}{$\begin{array}{l}\text { Cohen's } \\
\text { d }\end{array}$} & \multicolumn{2}{|c|}{ Mean \pm SD } & \multirow[t]{2}{*}{$\mathbf{t}$} & \multirow[t]{2}{*}{$\mathbf{p}$} & \multirow{2}{*}{$\begin{array}{c}\text { CI }(95 \%) \\
\text { LI-LS }\end{array}$} & \multirow{2}{*}{$\begin{array}{l}\text { Cohen's } \\
\text { d }\end{array}$} \\
\hline & Pre & Post & & & & & Pre & Post & & & & \\
\hline STAI & $\begin{array}{c}47.46 \pm \\
12.60\end{array}$ & $\begin{array}{c}39.69 \pm \\
15.51\end{array}$ & 2.15 & 0.052 & $-1.11-15.95$ & 0.54 & $\begin{array}{c}44.09 \pm \\
10.87\end{array}$ & $\begin{array}{c}39.63 \pm \\
13.95\end{array}$ & 1.39 & 0.193 & $-4.13-10.93$ & 0.35 \\
\hline BDI & $\begin{array}{c}13.16 \pm \\
6.52\end{array}$ & $\begin{array}{c}8.08 \pm \\
7.99\end{array}$ & 2.84 & 0.016 & $1.14-9.02$ & 0.69 & $\begin{array}{c}14.90 \pm \\
5.59\end{array}$ & $\begin{array}{c}10.63 \pm \\
8.64\end{array}$ & 2.81 & 0.018 & $0.88-7.65$ & 0.58 \\
\hline
\end{tabular}

SD: standard deviation, STAI: State-Trait Anxiety Inventory, BDI: Beck's depression index, CES: cranial electrical stimulation, LL: Iower limit, UL: upper limit, CI: confidence interval.

be useful to clarify the effect size of intervention with CES and placebo in an independent way.

Whereas the analysis of the effect size, the effect of the CES in the reduction of the severity of insomnia is large and medium in the placebo group. It is confirmed that both statistical significance and effect size had a higher effect of the CES over the placebo. It is possible that CES decreases the cortical hyperarousal, which is characteristic on insomnia; also, CES may increase the alpha activity, facilitating the induction of sleep ${ }^{37}$.

Furthermore, you can see that the size of the effect on the symptoms of anxiety is medium for the CES and small for placebo which may suggest a reappraisal of the effects of the intervention of the CES to be considered superior to placebo in the treatment of anxiety.

In relation to depression, with the effect size analysis, CES and placebo had moderate effects. Some studies indicate that CES is efficient in an equal or better way than the pharmacological treatment for depression ${ }^{38}$, but meta-analysis studies indicate that they are scarce systematized double-blind studies ${ }^{39}$, in this regard, one of them meet this experimental approach, but it did not find differences between CES treatment and placebo ${ }^{40}$. In this sense, our results are consistent with the study that employed the same device of stimulation, both by the statistical significance and effect size calculations; the CES was not superior to placebo in depression symptoms.

The study has some limitations that can focus on two aspects: (1) the size of the sample, to allow extending the statistical analyses, including the segmentation of the sample for analysis by sex and between different levels of severity of symptoms, (2) objective measurements at different levels of analysis both insomnia, anxiety, and depression symptoms (12). Separately, it was analyzed the effect of sleep hygiene and the combination with CES. It is proposed to compare the efficacy of the CES, other treatments, and their combination.

\section{Conclusions}

CES is a safe and efficient treatment for insomnia. The analysis of the effect suggests that this treatment can be clinically encouraging for anxiety, but its effect on depression is not superior to placebo.

\section{Declaration of conflicts of interest}

The authors reported no potential conflicts of interest.

\section{Financing}

No financial support was received for this scientific report.

\section{Ethical disclosures}

Protection of human and animal subjects. The authors declare that the procedures followed were in accordance with the regulations of the relevant clinical research ethics committee and with those of the Code of Ethics of the World Medical Association (Declaration of Helsinki).

Confidentiality of data. The authors declare that they have followed the protocols of their work center on the publication of patient data.

Right to privacy and informed consent. The authors have obtained the written informed consent of the patients or subjects mentioned in the article. The corresponding author is in possession of this document.

\section{References}

1. World Health Organization. Depression and Other Common Mental Disorders: Global Health Estimates. WHO Library Cataloguing-in-Publication Data. Geneva: World Health Organization; 2017.

2. American Academy of Sleep Medicine. International Classification of Sleep Disorders. Diagnostic and Coding Manual. $2^{\text {nd }}$ ed. Westchester, IL: American Academy of Sleep Medicine; 2005.

3. Bandelow B, Michaelis S. Epidemiology of anxiety disorders in the $21^{\text {st }}$ century. Dialogues Clin Neurosci. 2015;17:327-35. 
4. Lim GY, Tam WW, Lu Y, Ho CS, Zhang MW, Ho RC. Prevalence of depression in the community from 30 countries between 1994 and 2014 Sci Rep. 2018;8:2861.

5. Morin CM, Benca R. Chronic insomnia. Lancet. 2012;379:1129-41.

6. Craske MG, Stein MB. Anxiety. Lancet. 2016;388:3048-59.

7. Moo-Estrella J, Pérez-Benítez H, Solís-Rodríguez F, Arankowsky-Sandoval $G$. Evaluation of depressive symptoms and sleep alterations in college students. Arch Med Res. 2005;36:393-8.

8. Bouscoulet LT, Vázquez-García JC, Muiño A, Márquez M, López MV, de Oca MM, et al. Prevalence of sleep related symptoms in four Latin American cities. J Clin Sleep Med. 2008:4:579-85.

9. Bonnet MH, Arand DL. Hyperarousal and insomnia: state of the science. Sleep Med Rev. 2010;14:9-15

10. Levenson JC, Kay DB, Buysse DJ. The pathophysiology of insomnia Chest. 2015;147:1179-92.

11. Huang YJ, Lane HY, Lin CH. New treatment strategies of depression: based on mechanisms related to neuroplasticity. Neural Plast. 2017;2017:4605971.

12. Farach FJ, Pruitt LD, Jun JJ, Jerud AB, Zoellner LA, Roy-Byrne PP. Pharmacological treatment of anxiety disorders: current treatments and future directions. J Anxiety Disord. 2012;26:833-43.

13. Paris J. The mistreatment of major depressive disorder. Can J Psychiatry. 2014;59:148-51.

14. Schweitzer PK, Feren SD. Pharmacological treatment of insomnia. In: Clinical Handbook of Insomnia. Berlin, Germany: Springer Science and Business Media; 2017.

15. Rose KM, Taylor AG, Bourguignon C. Effects of cranial electrical stimulation on sleep disturbances, depressive symptoms, and caregiving appraisal in spousal caregivers of persons with Alzheimer's disease. App Nurs Res. 2009;22:119-25.

16. Lande RG, Gragnani C. Efficacy of cranial electric stimulation for the treatment of insomnia: a randomized pilot study. Complement Ther Med. 2013;21:8-13.

17. Camposo M, Oliva JC, Granero A, Palao DJ. Efectividad y coste-efectividad de la terapia electroconvulsiva de mantenimiento: un análisis naturalístico en espejo. Actas Esp Psiquiatr. 2017;45:257-67.

18. Goyatá SL, Avelino CC, Santos SV, Souza Junior DI, Gurgel MD, Terra Fde S. Effects from acupuncture in treating anxiety: integrative review. Rev Bras Enferm. 2016;69:602-9.

19. Farah WH, Alsawas M, Mainou M, Alahdab F, Farah MH, Ahmed AT, et al. Non-pharmacological treatment of depression: a systematic review and evidence map. Evid Based Med. 2016;21:214-21.

20. Liu S, Sheng J, Li B, Zhang X. Recent advances in non-invasive brain stimulation for major depressive disorder. Front Hum Neurosci. 2017:11:526.

21. Kirsch DL, Nichols F. Cranial electrotherapy stimulation for treatment of anxiety, depression, and insomnia. Psychiatr Clin North Am. 2013:36:169-76.

22. Antal A, Alekseichuk I, Bikson M, Brockmöller J, Brunoni AR, Chen R, et al. Low intensity transcranial electric stimulation: safety, ethical, legal regulatory and application guidelines. Clin Neurophysiol. 2017;128:1774-809.

23. Shekelle PG, Shekelle P, Cook I, Miake-Lye IM, Mak S, Booth MS, et al. The Effectiveness and Risks of Cranial Electrical Stimulation for the Treatment of Pain, Depression, Anxiety, PTSD, and Insomnia: a Systematic Review. VA Evidence-based Synth Progr Reports. Washington, DC: Department of Veterans Affairs (US); 2018.
24. Food and Drug Administration. Summary of Basis of Approval, Neurological Devices. Vol. 21. Silver Spring, Maryland: food and Drug Administration; 1979. Available from: https://www.accessdata.fda.gov/scripts/ cdrh/cfdocs/cfcfr/cfrsearch.cfm?fr $=882.5800$.

25. Feusner JD, Madsen S, Moody TD, Bohon C, Hembacher E, Bookheimer SY, et al. Effects of cranial electrotherapy stimulation on resting state brain activity. Brain Behav. 2012;2:211-20.

26. Kennerly R. QEEG analysis of cranial electrotherapy: a pilot study. J Neurother. 2004;8:112-3.

27. Morin CM, LeBlanc M, Bélanger L, Ivers H, Mérette C, Savard J. Prevalence of insomnia and its treatment in Canada. Can J Psychiatry. 2011;56:540-8

28. Spielberger CD, Gorsuch RL, Lushene RE. State-Trait Anxiety Inventory. Madrid: TEA; 1982.

29. Beck AT, Steer RA, Brown GK. Beck Depression Inventory. $2^{\text {nd }}$ ed. Buenos Aires: Paidós; 2006.

30. Cohen J. A power primer. Psychol Bull. 1992:112:155-9.

31. Yennurajalingam S, Kang DH, Hwu WJ, Padhye NS, Masino C, Dibaj SS, et al. Cranial electrotherapy stimulation for the management of depression, anxiety, sleep disturbance, and pain in patients with advanced cancer: a preliminary study. J Pain Symptom Manage. 2018; 55:198-206.

32. Hirshkowitz M, Whiton K, Albert SM, Alessi C, Bruni O, DonCarlos L, et al. National Sleep Foundation's updated sleep duration recommendations: final report. Sleep Health. 2015;1:233-43.

33. Murawski B, Wade L, Plotnikoff RC, Lubans DR, Duncan MJ. A systematic review and meta-analysis of cognitive and behavioral interventions to improve sleep health in adults without sleep disorders. Sleep Med Rev. 2018;40:160-9.

34. Kirsch DL, Gilula MF. CES in the treatment of insomnia: a review and meta-analysis. Pract Pain Manage. 2007;7:30-43.

35. Passini FG, Watson CG, Herder J. The effects of cerebral electric therapy (electrosleep) on anxiety, depression, and hostility in psychiatric patients. J Nerv Ment Dis. 1976;163:263-6.

36. Kalmbach DA, Cuamatzi-Castelan AS, Tonnu CV, Tran KM, Anderson JR, Roth $T$, et al. Hyperarousal and sleep reactivity in insomnia: current insights. Nat Sci Sleep. 2018;10:193-201.

37. Gilula MF, Kirsch DL. Cranial electrotherapy stimulation review: a safer alternative to psychopharmaceuticals in the treatment of depression. J Neurother. 2005;9:7-26

38. Kavirajan HC, Lueck K, Chuang K. Alternating current cranial electrotherapy stimulation (CES) for depression. Cochrane Database Syst Rev. 2014;7:CD010521.

39. Mischoulon D, De Jong MF, Vitolo OV, Cusin C, Dording CM, Yeung AS, et al. Efficacy and safety of a form of cranial electrical stimulation (CES) as an add-on intervention for treatment-resistant major depressive disorder: a three week double blind pilot study. J Psychiatr Res. 2015; 70:98-105.

40. Bhardwaj M, Arumugam N, Gambhir S. Efficacy of cranial electrical stimulation and rational emotive behavior therapy in improving psychological illness among chronic stroke survivors: a pilot randomized controlled trial. Ann Indian Acad Neurol. 2018;21:188-92. 